Original scientific paper

\title{
INFLUENCE OF THE INCLINED PIPE SECTION ON THE PERFORMANCE OF A WATERJET PROPULSION DEVICE
}

\author{
Chen, F. Y. ; Cheng, L. *\#; Wang, C. ${ }^{* * * *}$; Gao, Z. ${ }^{*} \&$ Luo, C. \\ ${ }^{*}$ College of Hydraulic Science and Engineering, Yangzhou University, Yangzhou, 225009 China \\ ${ }^{* * *}$ Hainan Vocational University of Science and Technology, Haikou 571126, China \\ E-Mail: chengli@yzu.edu.cn ( ${ }^{\#}$ Corresponding author)
}

\begin{abstract}
A waterjet propulsion device is a new type of propulsion system whose inlet passage affects the performance of the entire device. To study the influence of the inlet passage with an inclined pipe section (IPS) on the hydrodynamic characteristics of the device, a numerical method was used to determine the influences of IPS's length $L$ and rotational speed $n$ on hydraulic performance and thrust characteristics. Results show that the head $H$ of the device increases significantly from $3.29 \mathrm{~m}$ to $12.64 \mathrm{~m}$ as rotational speed $n$ increases $(700 \mathrm{r} / \mathrm{min}<n<1300 \mathrm{r} / \mathrm{min})$. Moreover, efficiency $\eta$ increases from $61.37 \%$ to $64.75 \%$ and then decreases to $60.99 \%$. $L$ exerts minimal effect on $\eta$, which reaches its maximum value when $n=900 \mathrm{r} / \mathrm{min}$ and $L=1.12 D$ ( $D$ is the outlet diameter of the inlet passage). Device thrust $F$ gradually increases with an increase in $n$, and the increase rate continues to rise, while $L$ has minimal effect on $F$. The results provide a reference for optimizing the inlet passage of a waterjet propulsion device. (Received in May 2021, accepted in June 2021. This paper was with the authors 2 weeks for 1 revision.)
\end{abstract}

Key Words: Waterjet Propulsion Device, Length of Inlet Passage, Rotational Speed, Hydrodynamic

\section{INTRODUCTION}

A waterjet propulsion device is a type of device that uses reactive force to obtain thrust. With the continuous development of modern fluid mechanics, waterjet propulsion devices exhibit the advantages of high efficiency, anti-cavitation performance, and good corrosion resistance when sailing. These devices have been widely used in high-performance ships in recent years. A waterjet propulsion device is primarily composed of a mechanical part, a hydraulic system, and a control system. As an important inlet structure of the device, the inlet passage determines the quality of the system. Therefore, efficiently designing the inlet passage is critical to satisfy requirements. In accordance with the contraction characteristic, the inlet passage can be generally divided into the contraction, elbow, and horizontal straight sections [1]. At present, the optimal design of pumps mainly uses theoretical modelling [2], numerical simulation [3, 4] and experimental verification [5]. Moreover, numerical simulation and experimental verification can be combined to explore the influences of various parameters, such as inlet velocity ratio and ship speed, on the hydraulic performance of the inlet passage and the hydraulic loss of each section of the inlet passage under different flow quantities and to implement multi-objective optimization of this passage [6-8]. However, only a few methods directly use numerical simulation to analyse the hydraulic performance of the inlet passage while considering its shrinkage characteristics. On the basis of multidisciplinary optimization design methods, the comprehensive performance of a pump impeller can be effectively improved by adjusting the geometric parameters of the trough structure and the lightweight design of the pump impeller while fully considering the influences of hydraulic power and structural design $[9,10]$. To study the flow characteristic of the inlet passage, UG NX, SolidWorks, and other software have been generally used to realize the parametric modelling of the inlet passage and create an optimization design of its structures, such as inclination and labial angles, in a waterjet propulsion device through numerical simulation using the CFD software Fluent $[11,12]$. The propulsion efficiency of a waterjet propulsion device and system 
applicability can be improved by reasonably designing the inlet passage. However, determining the geometric parameters of the inlet passage and the influence and influence degree of the conduit contraction device on the hydrodynamic characteristics of this device remains unknown.

On this basis, the influences of the geometric parameters of the inlet passage on hydrodynamic performance have been explored by researchers. However, when the submerged depth of the inlet passage is changed, the influence of the change in geometric parameters of the contraction section on the practical operation of a waterjet propulsion system has not been investigated. Therefore, designing reasonable geometric parameters of the contraction section and exploring the influence of their changes on system performance are urgent issues. In the current study, different lengths of inclined pipes were selected, and rotational speed was changed to analytically explore the changes in the hydraulic performance of this device under different working conditions via CFD numerical simulation. The results of this study cannot only be used to optimize the inlet passage of a waterjet propulsion device but can also enrich related theories.

\section{STATE OF THE ART}

At present, researchers have conducted several studies on the inlet passage of waterjet propulsion devices. Engeda et al. [13] examined flow quantity through numerical simulation and analysed the influence of the inlet passage on the performance of a waterjet propulsion device. However, they did not consider the influence of ship body under actual working conditions. By analytically studying parameters, such as flow velocity and pressure, Kang et al. [14] determined that device performance was superior and thrust was larger when the angles of incidence and emergence of conduit were $30^{\circ}$; however, they disregarded the influence of change in rotational speed on device performance. Rodionov et al. [15] designed three inlet passage models with bias voltage through numerical simulation, effectively improving the stability of ship propulsion under intense sea waves. However, they did not consider the performance of the propulsion device under parametric changes, such as navigational speed. Choi et al. [16] added a member bar in front of the vane to generate nonuniform conduit water flow and observed the heat transfer characteristic on the end wall; however, they did not study parametric changes, such as flow velocity, in the conduit. Cao et al. [17] used the CFD method to calculate the hydraulic loss distribution of a waterjet propulsion device, and their calculation results showed that the loss in the propulsion pump was the highest, accounting for approximately half, followed by the loss inside the inlet passage. Wang et al. [18] designed different water inlet angles of the impeller blade and explored the influences of changes in the water inlet angle on the flow quantity and efficiency of the pump section on the basis of CFD. Eslamdoost et al. [19] numerically simulated water flow distribution around a ship during navigation to determine the propulsion efficiency of a waterjet propulsion device but did not explore the influences of changes in structural geometric parameters, such as the inlet passage in the device, on its thrust. Park et al. [20] compared the flow line and pressure distribution obtained through numerical simulation and experiment to understand flow characteristics in the inlet passage and predict the position of stagnation point in the labial part. Dyakova et al. [21] improved the propulsion efficiency of the device by changing the position of the water inlet through a numerical fluid dynamics method but did not analyse the relationship between water inlet angle and conduit length. On the basis of the basic principle of waterjet propulsion, Kortunova and Yakovleva [22] evaluated water flow at the inlet passage of a waterjet propulsion device in a self-propulsion test and described the influence of its coverage area on induction efficiency. However, this test was implemented on a test bed, and ship state under actual working conditions was not considered. Wang et al. [23] performed a numerical 
calculation by setting different numbers of grids and found that the inlet grids will degrade the flow performance of the inlet passage and the propulsion performance of a waterjet propulsion device. Huang et al. [24] optimized the structural parameters of a waterjet propulsion device by using CFD, effectively improving the thrust and discharge capacity of the device. Takai et al. [25] used the CFD method to analyse an existing device, and thus, improve and optimally design a waterjet propulsion system. However, they did not explore how the inlet passage can be optimally designed to improve water inlet efficiency. Huang and Luo [26] numerically simulated an inlet passage to improve the understanding of its flow characteristics and determine how to reduce hydraulic loss effectively.

The optimization design of the inlet passage and the thrust and efficiency of a waterjet propulsion device have been explored in the aforementioned studies mostly in terms of the geometric parameters of the inlet section of the inlet passage or the flow characteristics in this section. By contrast, the contract characteristics of the inlet passage have been rarely explored, along with the influence of the length change of the inclined pipe section (IPS) in the inlet passage on the hydrodynamic characteristics of a waterjet propulsion device. In the current study, a numerical simulation technology was used to study the influence of changes in the geometric parameters of the contraction section on the performance of a waterjet propulsion device. It intends to provide a reference for the length selection and performance optimization of the inlet passage.

The remainder of this study is organized as follows: Section 3 describes the numerical simulation method, calculation case, and analytical parameters. Section 4 presents the analysis of the hydraulic performance, flow characteristics, and thrust performance of a waterjet propulsion device in accordance with the numerical simulation results. The final section summarizes the study and provides the related conclusions.

\section{METHODOLOGY}

\subsection{Computational domain and meshing}

Factors, such as the boundary layer of a ship body, will affect kinetic energy at the inlet of the inlet passage and further influence the accuracy of the numerical simulation results. Therefore, the flow field-controlled body should include the fluid in the inlet passage and around the inlet of the inlet passage. A cuboid was placed beneath the inlet passage; and the length, width, and height of this flow field-controlled body were $30 D, 10 D$, and $8 D$, respectively ( $D$ is the outlet diameter of the inlet passage), which could be seen in Fig. 1.

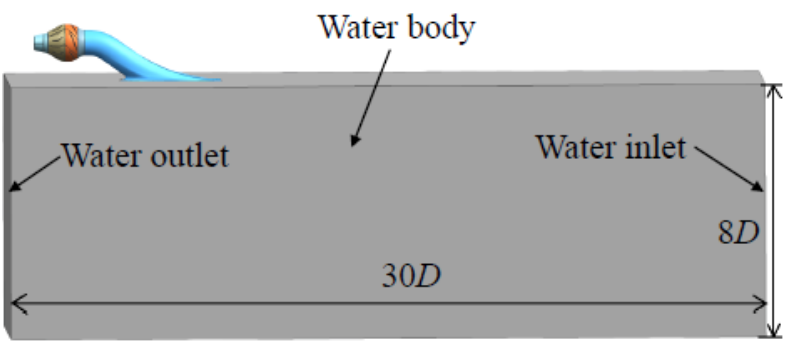

a)

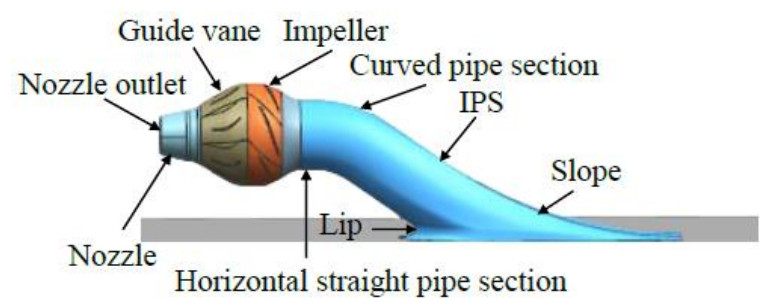

b)

Figure 1: Computational domain, a) water body domain, b) waterjet propulsion domain.

On the basis of ANSYS-ICEM, each computational subdomain was meshed using structured grid, as shown in Fig. 2. In the current study, it was necessary to analyse the grid independence of the inlet passage. Grid density was changed by altering the grid size of the inlet passage. The results showed that the efficiency of the waterjet propulsion device changed minimally when the number of grids in the inlet passage exceeded 1,350,000. 


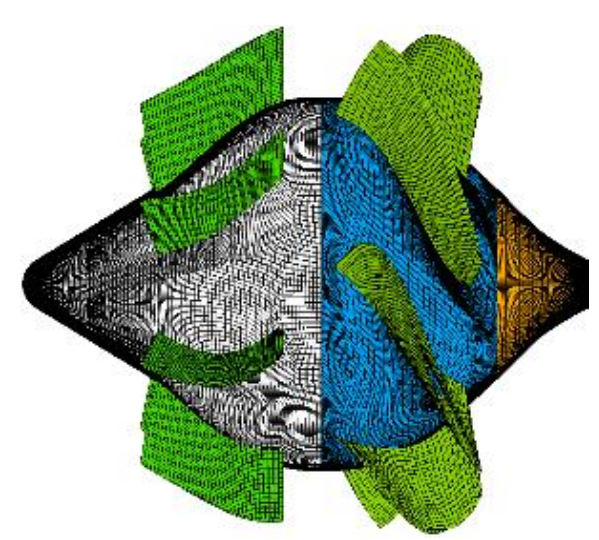

a)

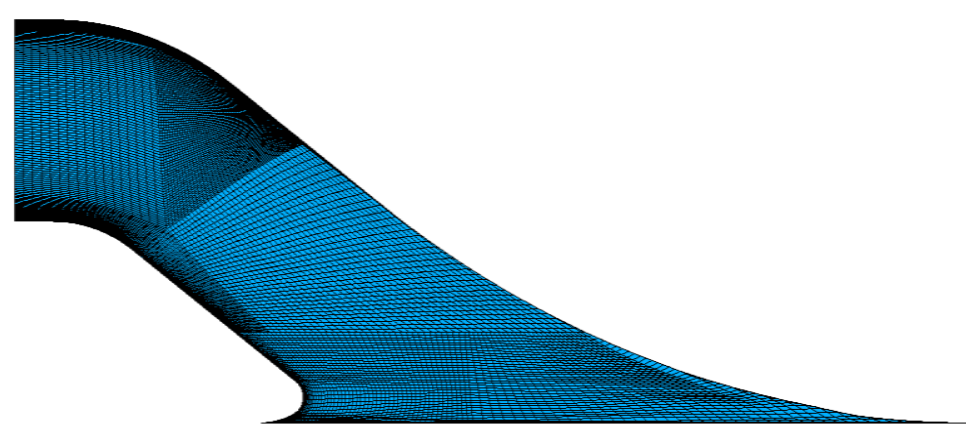

b)

Figure 2: Meshing of different computational domain, a) impeller and diffuser, b) inlet passage.

\subsection{Boundary conditions}

The inlet boundary of the water body was set as the velocity inlet located sufficiently far from the waterjet propulsion device, and the velocity was $8 \mathrm{~m} / \mathrm{s}$, i.e., the navigational speed was $8 \mathrm{~m} / \mathrm{s}$. The average static pressure was set at the water outlet, with a reference pressure of $1 \mathrm{~atm}$. Four planes, which contained the nozzle, guide vane, impeller, pump shaft, inlet passage, and water body at the hull bottom, were set as the wall surface boundaries and processed using a scalable wall surface function. The interface between the impeller inlet and outlet sections was set as a static-dynamic interface, while the others were set as static-static interfaces. Rotational speed was set to $700,900,1,100$, and $1,300 \mathrm{r} / \mathrm{min}$.

\subsection{Calculation case}

The two-dimensional geometrical model of the inlet passage was connected using 13 parameters, and the constraint relations among these parameters were realized through the expression-rough drawing association function of the UG NX software. The two-dimensional structure of the inlet passage is shown in Fig. 3. To explore the influence of inlet passage length on the performance of the entire waterjet propulsion device, three cases (Table I) were designed by changing the length of the IPS of the inlet passage, and then the hydrodynamic characteristics of the waterjet propulsion device under IPS lengths of $0.6 L, L$, and $1.4 L(L=1.12 D ; D$ is the diameter of the conduit outlet, $\mathrm{mm}$ ) were analysed.

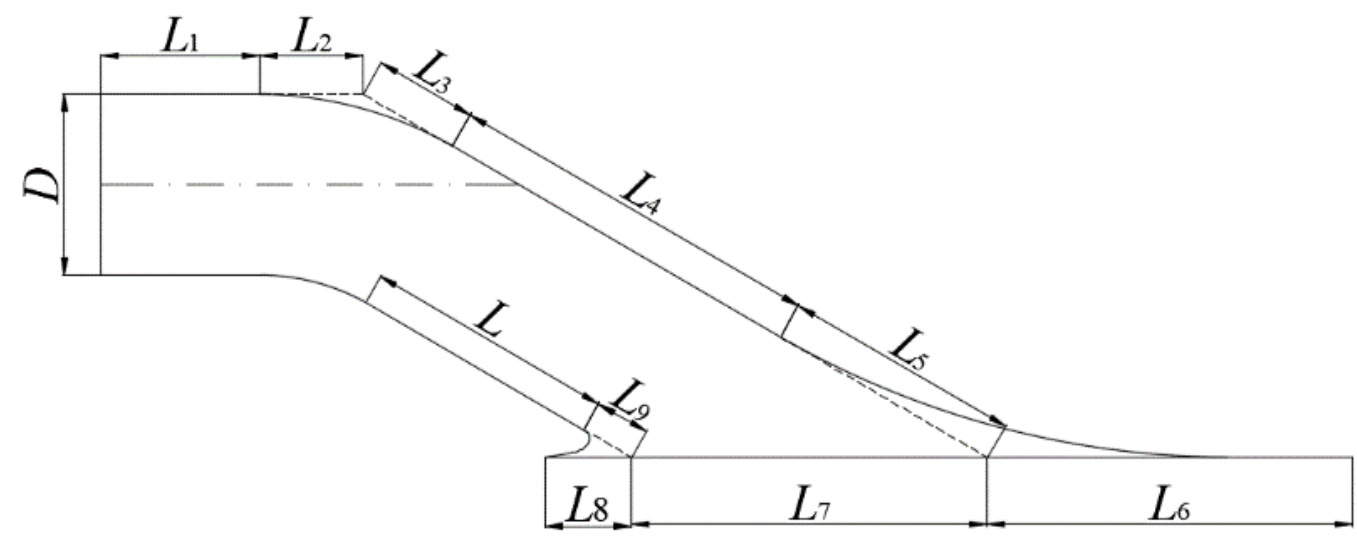

Figure 3: Two-dimensional structure of the inlet passage. 
Table I: Study case.

\begin{tabular}{|c|c|c|}
\hline Case & $\begin{array}{c}\text { Length of the inclined } \\
\text { pipe section }\end{array}$ & Diagram \\
\hline Case I & $0.6 \mathrm{~L}$ & \\
\hline Case II & $L$ & \\
\hline Case III & $1.4 L$ & \\
\hline
\end{tabular}

\section{RESULTS ANALYSIS AND DISCUSSION}

\subsection{Hydraulic performance}

The numerical calculation results were compared intuitively and conveniently under different working conditions. The rotational speed and efficiency at other operating points were normalized by taking the efficiency of the waterjet propulsion device in Case II at a rotational speed of $700 \mathrm{r} / \mathrm{min}$ as the benchmark. Four operating points were considered in the calculation. The conduit length at the optimal operating point was Case II, corresponding to the flow velocity of $900 \mathrm{r} / \mathrm{min}$. The rotational speed at one operating point was lower than that at the optimal operating point. The variation trend lines of hydraulic performance and the efficiency of the waterjet propulsion device with the rotational speed are displayed in Fig. 4. As shown in the figure, efficiency change was minor under all three cases. Overall, device efficiency was relatively higher under Case II and was superior to the other instances when the rotational speed was $900 \mathrm{r} / \mathrm{min}$. The efficiency curve presented an increasing and then declining trend. After reaching the peak value at the rotational speed of $900 \mathrm{r} / \mathrm{min}$, efficiency continuously degraded with the continuous increase in the rotational speed. The conduit length greatly impacted the efficiency at a low rotational speed, but the effect was minor at a high rotational speed. After the rotational speed reached $900 \mathrm{r} / \mathrm{min}$, the conduit length almost did not influence the waterjet propulsion device. Table II shows that the heads of the three schemes tended to be equal as the speed increased.

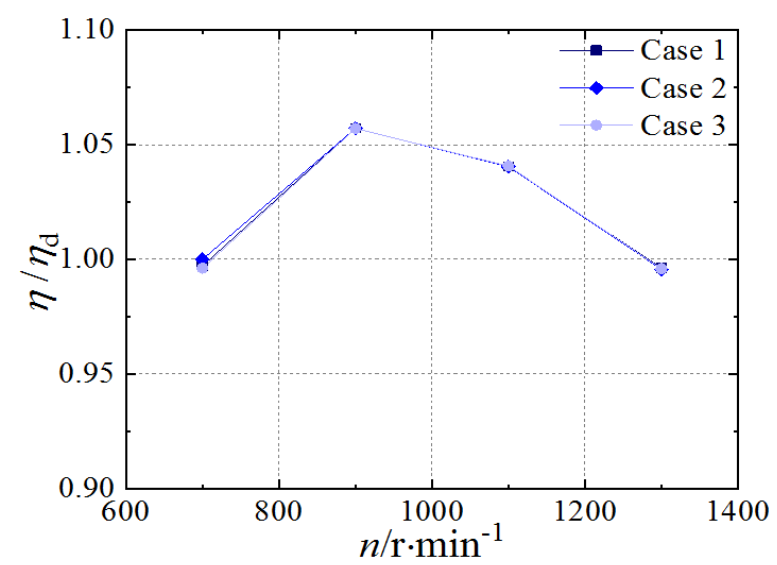

Figure 4: Variation trend lines of hydraulic performance and efficiency of the waterjet propulsion device with rotational speed. 
Table II: Hydraulic performance of the waterjet propulsion device.

\begin{tabular}{|c|c|c|c|}
\hline \multirow{2}{*}{$\begin{array}{c}\boldsymbol{n} \\
(\mathrm{r} / \mathrm{min})\end{array}$} & Case I & Case II & Case III \\
\cline { 2 - 4 } & \multicolumn{3}{|c|}{ Head $(\mathrm{m})$} \\
\hline 700 & 3.27 & 3.29 & 3.32 \\
\hline 900 & 5.85 & 5.87 & 5.88 \\
\hline 1,100 & 8.94 & 8.95 & 8.95 \\
\hline 1,300 & 12.63 & 12.65 & 12.64 \\
\hline
\end{tabular}

\subsection{Flow characteristics}

The three-dimensional side views of the flow regime inside the inlet passage under the same conduit length and different rotational speeds are shown in Fig. 5. The comparison of the subgraphs showed that, under a constant conduit length, the water flowed into the device through the conduit along the hull bottom. With the continuous increase in the rotational speed, the spiral flow and backflow gradually disappeared. At the rotational speed of $700 \mathrm{r} / \mathrm{min}$, heavy spiral flow and backflow were symmetrically distributed at two upper sides of the conduit in the inclined pipe and elbow sections. This spiral flow filled the upper part of the whole conduit. The backflow range was also extensive, filling nearly $1 / 3$ of the conduit space. Both flows generate a severe impact on the operation and performance of the whole waterjet propulsion device. At the rotational speed of $900 \mathrm{r} / \mathrm{min}$, the spiral flow almost disappeared, and the backflow was mitigated somehow. When the rotational speed was elevated to $1,100 \mathrm{r} / \mathrm{min}$, the spiral flow already disappeared, and the backflow was gradually reduced. When the rotational speed was further increased to $1,300 \mathrm{rpm}$, the spiral flow disappeared, and the water flow tended to be smooth in the conduit.

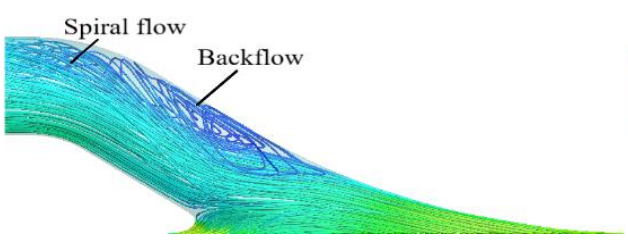

a)

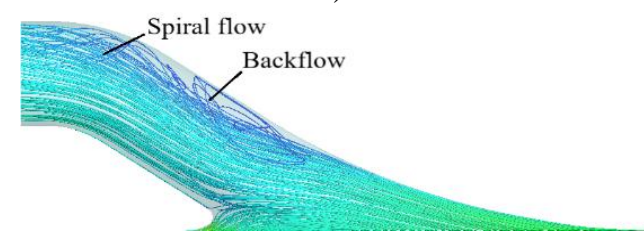

c)

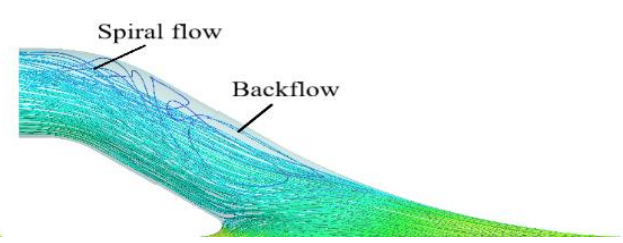

b)

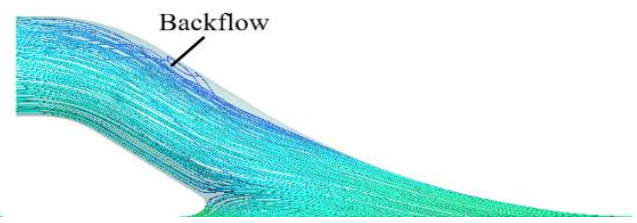

d)

Figure 5: Three-dimensional side views of flow regime in inlet passage at different rotational speed, a) $n=700 \mathrm{r} / \mathrm{min}$, b) $n=900 \mathrm{r} / \mathrm{min}$, c) $n=1100 \mathrm{r} / \mathrm{min}$, d) $n=1300 \mathrm{r} / \mathrm{min}$.

The three-dimensional side view of the flow regime in the inlet passage at the rotational speeds of $900 \mathrm{r} / \mathrm{min}$ and different conduit lengths are displayed in Fig. 6 . The conduit length in Fig. $6 \mathrm{a}$ appeared to be Case I, that in $6 \mathrm{~b}$ belonged to Case II, and that in $6 \mathrm{c}$ belonged to Case III. At a constant rotational speed, the water flowed into the device through the conduit along the hull bottom. When the rotational speed is $900 \mathrm{r} / \mathrm{min}$, the spiral flow and backflow symmetrically distributed at two upper sides of the conduit in the inclined pipe section and bent pipe section in Case I are most severe, seriously impacting the operation and performance of the whole waterjet propulsion device. With the increase in the conduit length, the backflow and spiral flow phenomena were gradually mitigated. The backflow and spiral flow were at the minimum in the inlet passage under Case III, and the water flow was the smoothest in the conduit. 


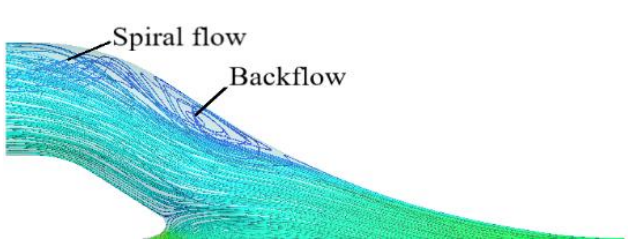

a)

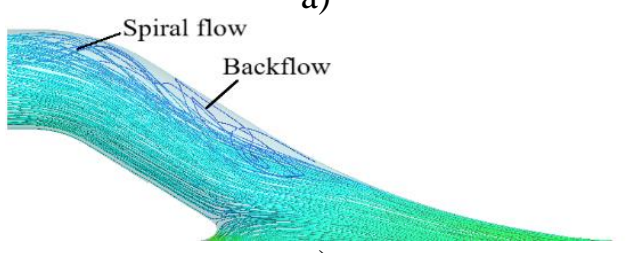

c)

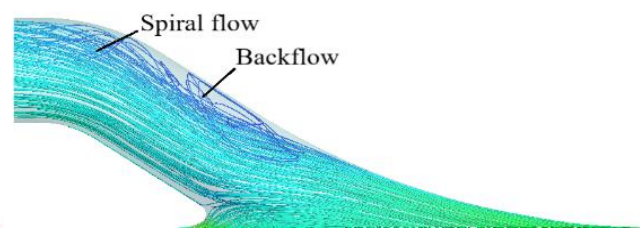

b)

Figure 6: Three-dimensional side views of flow regime in the inlet passage of the waterjet propulsion device at a rotational speed of $900 \mathrm{r} / \mathrm{min}$, a) Cases I, b) Case II, c) Case III.

\subsection{Wingspan characteristics}

The graphs of the impeller wingspan at different rotational speed values with the conduit length under Case II are shown in Fig. 7. The upper, middle, and lower span values in each graph were 0.1, 0.6, and 0.9, respectively $(700,900,1,100$, and 1,300 r/min in Figs. 7 a, b, c, and d, respectively). The results showed that the pressure on the vane was continuously increased with the increase in the rotational speed. At the rotational speed of $900 \mathrm{r} / \mathrm{min}$, a negative pressure zone appeared on the suction surface of the vane close to the impeller's inlet section, and the pressure close to the wheel flange was higher than that close to the wheel hub. Consequently, the wheel hub was more susceptible to cavitation-induced damage than the wheel flange. As the rotational speed increased, the negative pressure zone expanded, and the negative pressure was continuously enlarged. When the rotational speed was $1,300 \mathrm{r} / \mathrm{min}$, almost the whole suction surface of the vane was in the negative pressure zone, and the water flow was cut off on the suction surface of the vane because of the cavitation. As a result, the efficiency of the waterjet propulsion device experiences substantial degradation, thus failing to work normally. At the same rotational speed, the pressure distribution close to the wheel hub was more uniform than that close to the wheel flange. When the rotational speed was $1,300 \mathrm{r} / \mathrm{min}$, the maximum difference in the value of the pressure distribution in the vane was observed, and the structure was the least stable. The lower the rotational speed, the smaller the difference value between the maximum and minimum values of vane pressure, the smaller the variation amplitude, and the better it was for the operational stability of the waterjet propulsion device.

The graphs of the streamline distribution of the impeller wingspan at different rotational speed values with the length of inlet passage under Case II are shown in Fig. 8. The upper, middle, and lower span values of each graph were $0.1,0.6$, and $0.9(700,900,1,100$, and $1,300 \mathrm{r} / \mathrm{min}$ in Figs. $8 \mathrm{a}, \mathrm{b}, \mathrm{c}$, and d). At a relatively low rotational speed, the flow regime distribution in the impeller was relatively uniform. With the continuous increase in the rotational speed, the internal fluid velocity of the impeller was continuously elevated, the flow regime distribution became less uniform, and an obvious low-velocity zone appeared at the impeller close to the wheel flange. At the impeller velocity of $700 \mathrm{r} / \mathrm{min}$, the streamline distribution was uniform close to the wheel hub, the flow velocity slightly changed, the vane suction surface close to the wheel flange was a high-velocity zone, and the vane pressure surface was a low-velocity zone. As the rotational speed was accelerated, the variation amplitude of fluid velocity at all parts in the impeller was enlarged, and the difference value between the high-velocity flow and the low-velocity flow was also increased. At a rotational speed of $1,300 \mathrm{r} / \mathrm{min}$, the flow velocity of the whole impeller structure changed violently; an obvious low-velocity zone appears close to the wheel flange of the impeller. Furthermore, most of the vane pressure surface was located within the low-velocity zone, and the partial vane suction 
surface was located in the high-velocity zone. A high-velocity zone appeared at the middle of the impeller, and over half of the vane suction surface was inside the high-velocity zone.
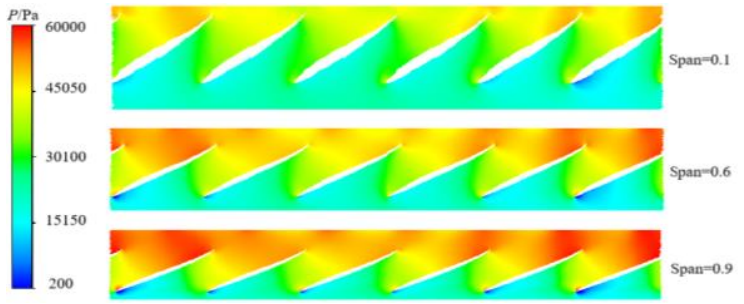

a)

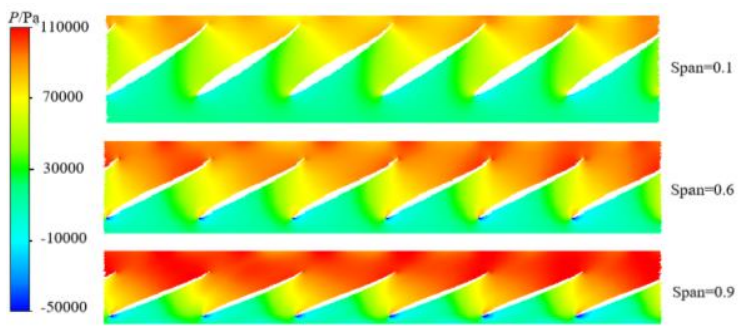

c)

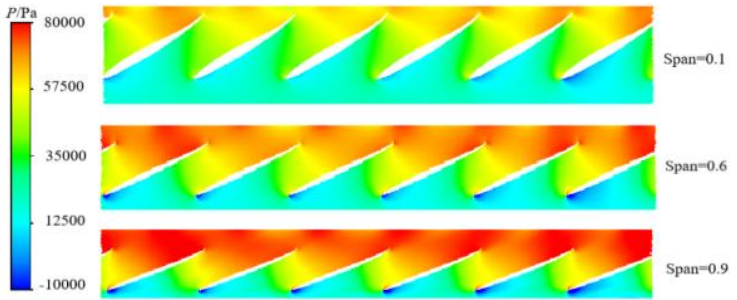

b)

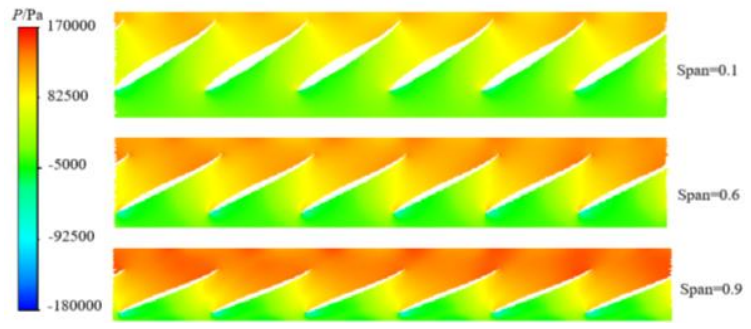

d)

Figure 7: Cloud pictures of impeller wingspan pressure distribution at different rotational speeds, a) $n=700 \mathrm{r} / \mathrm{min}$, b) $n=900 \mathrm{r} / \mathrm{min}$, c) $n=1100 \mathrm{r} / \mathrm{min}$, d) $n=1300 \mathrm{r} / \mathrm{min}$.

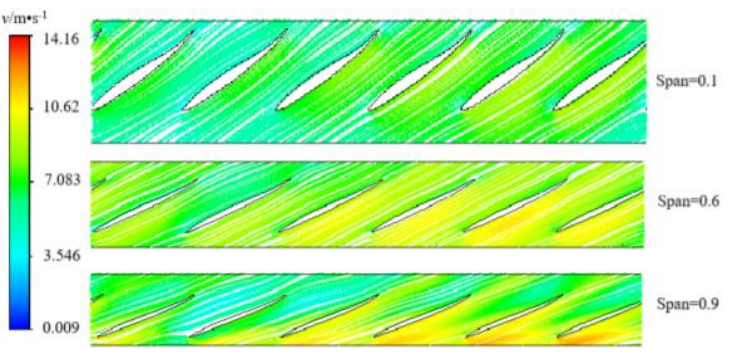

a)

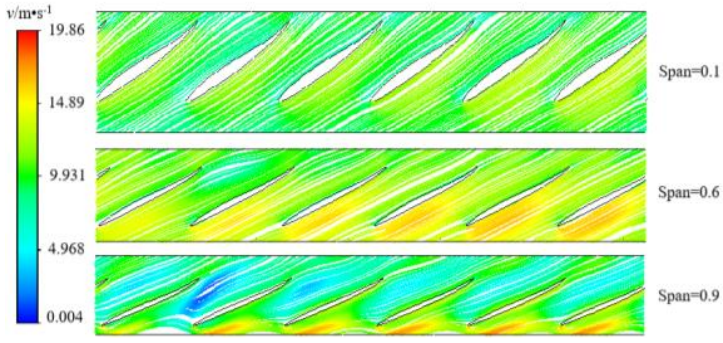

c)

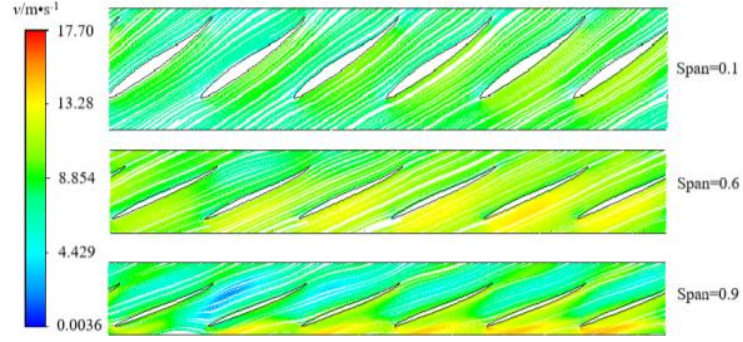

b)

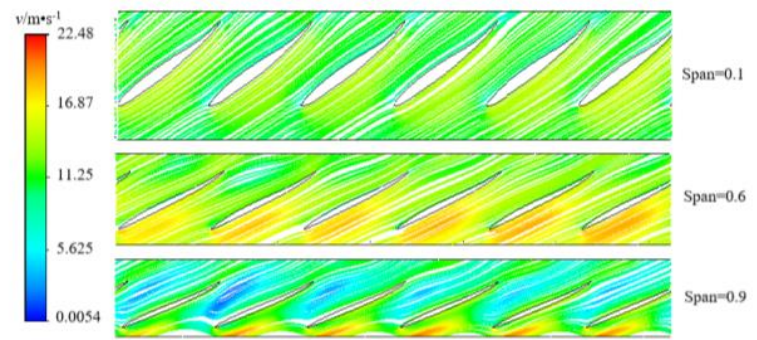

d)

Figure 8: Streamline distribution graphs of impeller wingspan at different rotational speeds, a) $n=700 \mathrm{r} / \mathrm{min}$, b) $n=900 \mathrm{r} / \mathrm{min}$, c) $n=1100 \mathrm{r} / \mathrm{min}$, d) $n=1300 \mathrm{r} / \mathrm{min}$.

\subsection{Uniform characteristics of flow velocity}

The uniformity of axial velocity distribution on the outlet section of the inlet passage is shown in Fig. 9. The results showed that the uniformity of axial velocity on the outlet section was enhanced with the increase in the rotational speed. With the further elevation of rotational speed, the velocity uniformity grew slowly and tended to be identical. At the same rotational speed, Case I obtained the poorest velocity uniformity, whereas Case III harvested the best velocity uniformness. At the rotational speed of $700 \mathrm{r} / \mathrm{min}$, the velocity uniformity under Case III was higher than those under Cases I and II. At the rotational speed of 1,300 r/min, the velocity uniformities under the three cases tended to be equal. 


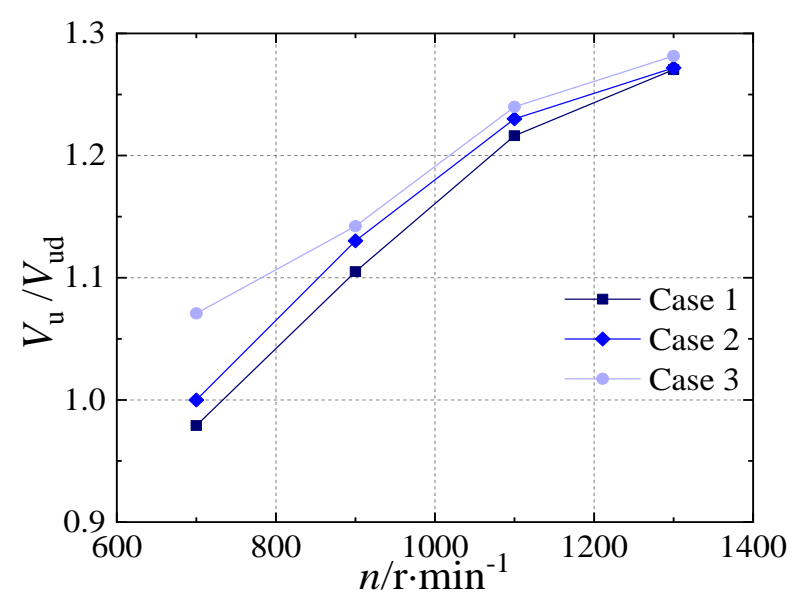

Figure 9: Uniformity of axial velocity distribution on the outlet section of the inlet passage.

\subsection{Thrust characteristics}

The thrust diagram of the waterjet propulsion device under different conditions is shown in Table III. The thrust increased with the rise in the rotational speed. With the increase in the rotational speed under the same conduit length, the thrust forces of the waterjet propulsion device under all three cases were increased, and the amplitude was enlarged with the increase in the rotational speed. At the same rotational speed, the thrust of the waterjet propulsion device was the maximum under Case II. As the conduit length was increased by $0.4 L$ and shortened by $0.4 \mathrm{~L}$, the thrust declined, indicating that the proper conduit length is suitable for ship navigation. As the rotational speed was elevated, the thrust forces of the waterjet propulsion device under the three cases tended to be consistent, indicating that the rotational speed had little effect on the thrust variation of different cases.

Table III: Thrust diagram of waterjet propulsion device.

\begin{tabular}{|c|c|c|c|}
\hline \multirow{2}{*}{$\begin{array}{c}n \\
(\mathrm{r} / \mathrm{min})\end{array}$} & Case I & Case II & Case III \\
\cline { 2 - 4 } & \multicolumn{3}{|c|}{ Thrust $(\mathrm{N})$} \\
\hline 700 & 373.42 & 379.94 & 371.43 \\
\hline 900 & 733.18 & 733.59 & 727.27 \\
\hline 1,100 & $1,169.02$ & $1,170.55$ & $1,166.63$ \\
\hline 1,300 & $1,734.93$ & $1,741.32$ & $1,738.63$ \\
\hline
\end{tabular}

\section{CONCLUSION}

A CFD study was carried out on the influences of the length of the IPS and rotational speed on the performance of the waterjet propulsion device to select the length of inlet passage better and avoid the operation under unfavourable submerged water depth. The conclusions are as follows:

(1) When only the rotational speed is considered, the efficiency increases and decreases with the rotational speed. The passage length influences the efficiency considerably at a low rotational speed, but the influence is minor at a high rotational speed. The waterjet propulsion device reaches the highest efficiency at the rotational speed of $900 \mathrm{r} / \mathrm{min}$ with the conduit length under Case II.

(2) The uniformity of axial velocity on the outlet section is improved with the increase in the rotational speed. As the rotational speed reaches a specific value, the velocity uniformity grows slowly with the elevation of rotational speed. 
(3) The thrust of the waterjet propulsion device increases with rotational speed. The thrust forces under all three cases increase, and the amplitude rises with the increase in the rotational speed.

(4) When only the conduit length is considered, all waterjet propulsion device performance indexes under the conduit length designed in Case II, mainly when the length of the IPS is $L$, are better than those of the other cases.

In this study, the numerical simulation and experimental verification are combined, and the length of inlet passage and rotational speed under the optimal operating conditions are given, thus providing a reference for the length selection of inlet passage and performance optimization. However, no detailed analysis is shown in the optimization design of the inlet passage, and the study is carried out mainly based on experience accumulation. Thus, more geometric parameters of inlet passage can be changed to optimize further the conduit structure and performance of the device.

\section{ACKNOWLEDGEMENT}

The study was supported by the Open Research Subject of Key Laboratory of Fluid and Power Machinery (Xihua University), and the Ministry of Education (No. szjj2019-018).

\section{REFERENCES}

[1] Luo, C.; Liu, H.; Cheng, L.; Wang, C.; Jiao, W. X.; Zhang, D. (2019). Unsteady flow process in mixed waterjet propulsion pumps with nozzle based on computational fluid dynamics, Processes, Vol. 7, No. 12, Paper 910, 21 pages, doi:10.3390/pr7120910

[2] Hernandez-Ramírez, G.; Leon-Segovia, Á. M.; Salazar, E.; Beltran-Reyna, R.; Tarragó, J. C. P. (2019). Mathematical modeling of the load correction coefficient of the lateritic of hydromixtures pumping, DYNA, Vol. 86, No. 208, 19-27, doi:10.15446/dyna.v86n208.72006

[3] Al-Obaidi, A. R.; Mohammed, A. A. (2019). Numerical investigations of transient flow characteristic in axial flow pump and pressure fluctuation analysis based on the CFD technique, Journal of Engineering Science and Technology Review, Vol. 12, No. 6, 70-79, doi:10.25103/ jestr.126.09

[4] Wang, H. L.; Hu, Q. X.; Yang, Y.; Wang, C. (2021). Performance differences of electrical submersible pump under variable speed schemes, International Journal of Simulation Modelling, Vol. 20, No. 1, 76-86, doi:10.2507/IJSIMM20-1-544

[5] Shi, L. J.; Zhu, J.; Tang, F. P.; Wang, C. (2020). Multi-disciplinary optimization design of axialflow pump impellers based on the approximation model, Energies, Vol. 13, No. 4, Paper 779, 19 pages, doi:10.3390/en13040779

[6] Huang, R. F.; Ye, W. X.; Dai, Y. X.; Luo, X. W.; Wang, Y. W.; Du, T. Z.; Huang, C. G. (2020). Investigations into the unsteady internal flow characteristics for a waterjet propulsion system at different cruising speeds, Ocean Engineering, Vol. 203, Paper 107218, 15 pages, doi:10.1016/j.oceaneng.2020.107218

[7] Jiao, W. X.; Cheng, L.; Zhang, D.; Zhang, B. W.; Su, Y. P.; Wang, C. (2019). Optimal design of inlet passage for waterjet propulsion system based on flow and geometric parameters, Advances in Materials Science and Engineering, Vol. 2019, Paper 2320981, 21 pages, doi:10.1155/ 2019/2320981

[8] Durán-Grados, V.; Mejías, J.; Musina, L.; Moreno-Gutiérrez, J. (2018). The influence of the waterjet propulsion system on the ships' energy consumption and emissions inventories, Science of the Total Environment, Vol. 631-632, 496-509, doi:10.1016/j.scitotenv.2018.02.291

[9] Wang, H. L.; Long, B.; Wang, C.; Han, C.; Li, L. J. (2020). Effects of the impeller blade with a slot structure on the centrifugal pump performance, Energies, Vol. 13, No. 7, Paper 1628, 17 pages, doi: $10.3390 /$ en 13071628

[10] Wang, C.; Chen, X. X.; Qiu, N.; Zhu, Y.; Shi, W. D. (2018). Numerical and experimental study on the pressure fluctuation, vibration, and noise of multistage pump with radial diffuser, Journal of 
the Brazilian Society of Mechanical Sciences and Engineering, Vol. 40, No. 10, Paper 481, 15 pages, doi:10.1007/s40430-018-1355-6

[11] Eslamdoost, A.; Vikström, M. (2019). A body-force model for waterjet pump simulation, Applied Ocean Research, Vol. 90, Paper 101832, 9 pages, doi:10.1016/j.apor.2019.05.017

[12] Gong, J.; Guo, C.-Y.; Wang, C.; Wu, T.-C.; Song, K.-W. (2019). Analysis of waterjet-hull interaction and its impact on the propulsion performance of a four-waterjet-propelled ship, Ocean Engineering, Vol. 180, 211-222, doi:10.1016/j.oceaneng.2019.04.002

[13] Engeda, A.; Kim, Y.; Aungier, R.; Direnzi, G. (2003). The inlet flow structure of a centrifugal compressor stage and its influence on the compressor performance, Journal of Fluids Engineering, Vol. 125, No. 5, 779-785, doi: 10.1115/1.1601255

[14] Kang, M.-K.; Park, D.-J.; Kang, H.-B.; Lee, S.-S. (2011). Performance analysis based on impeller inlet \& outlet angle for waterjet, Journal of Aerospace System Engineering, Vol. 5, No. 2, 27-32, doi:10.20910/JASE.2011.5.2.027

[15] Rodionov, V.; Sverchkov, A.; Rudnichenko, A.; Mamontov, F.; Ermolaev, A. (2020). Experimental and numerical studies of boat waterjets with increased seakeeping performance, Transactions of the Krylov State Research Centre, Vol. 4, 31-42, doi:10.24937/2542-2324-20204-394-31-42

[16] Choi, W.; Jung, K. J.; Park, J. S. (2020). Characteristics of heat transfer on a turbine blade endwall under various inlet flow conditions, Experimental Heat Transfer, Published online, 17 pages, doi: $10.1080 / 08916152.2020 .1811804$

[17] Cao, P.; Yang, W.; Li, G.; Cui, Y.; Gang, Y. (2014). Numerical hydraulic efficiency analysis of waterjet propulsion, $6^{\text {th }}$ International Symposium on Fluid Machinery and Fluid Engineering, Paper 1245, 8 pages, doi:10.1049/cp.2014.1245

[18] Wang, H. L.; Long, B.; Yang, Y.; Xiao, Y.; Wang, C. (2020). Modelling the influence of inlet angle change on the performance of submersible well pumps, International Journal of Simulation Modelling, Vol. 19, No. 1, 100-111, doi:10.2507/IJSIMM19-1-506

[19] Eslamdoost, A.; Larsson, L.; Bensow, R. (2016). Net and gross thrust in waterjet propulsion, Journal of Ship Research, Vol. 60, No. 2, 78-91, doi:10.5957/jsr.2016.60.2.78

[20] Park, W.-G.; Yun, H. S.; Chun, H. H.; Kim, M. C. (2005). Numerical flow simulation of flush type intake duct of waterjet, Ocean Engineering, Vol. 32, No. 17-18, 2107-2120, doi:10.1016/ j.oceaneng.2005.03.001

[21] Dyakova, T.; Rozhdestvensky, S.; Marinich, N.; Rudnichenko, A. (2020). Computational and experimental determination of waterjet aeration exposure in waves, Transactions of the Krylov State Research Centre, Vol. 4, 21-30, doi:10.24937/2542-2324-2020-4-394-21-30

[22] Kortunova, Y.; Yakovleva, O. (2018). Waterjet wake fraction assessment as per model test data, Transactions of the Krylov State Research Centre, Vol. 3, 41-49, doi:10.24937/2542-2324-20183-385-41-49

[23] Wang, S.; Wang, Y.; Jin, S.; Ding, J. (2013). Effect of inlet grid on duct flow performance and waterjet propulsion performance, Journal of Mechanical Engineering, Vol. 2013, No. 14, 164-169, doi:10.3901/JME.2013.14.164

[24] Huang, G.; Jin, Y.; Xuan, L.; Zhu, Y. X. (2011). Optimization for nozzle parameters of waterjet propulsion system, Information Journal, Vol. 14, No. 12, 3897-3904

[25] Takai, T.; Kandasamy, M.; Stern, F. (2011). Verification and validation study of URANS simulations for an axial waterjet propelled large high-speed ship, Journal of Marine Science and Technology, Vol. 16, No. 4, 434-447, doi:10.1007/s00773-011-0138-x

[26] Huang, R.; Luo, X. (2019). Numerical investigation of an intake duct for a waterjet propulsion system using modified partially averaged Navier-Stokes method, ASME-JSME-KSME $20198^{\text {th }}$ Joint Fluids Engineering Conference, Paper V03AT03A053, 6 pages, doi:10.1115/ $\underline{\text { AJKFluids2019-5059 }}$ 